\title{
级埌 \\ Evaluation of the Possibilities of Sodium Silicate Sands Application in Automated Hot-Box Process of Cores Shooting
}

\author{
M. Stachowicz *, K. Granat, P. Obuchowski \\ Department of Foundry Engineering, Plastics and Automation, Wroclaw University of Technology, \\ ul. Smoluchowskiego 25, 50-372 Wrocław, Poland \\ * Corresponding author: E-mail address: mateusz.stachowicz@pwr.edu.pl
}

Received 13.04.2017; accepted in revised form 07.06.2017

\begin{abstract}
The paper presents the results of preliminary research on the use of silica sands with hydrated sodium silicate $1.5 \%$ wt. of binder for the performance of eco-friendly casting cores in hot-box technology. To evaluate the feasibility of high quality casting cores performed by the use of this method, the tests were made with the use of a semiautomatic core shooter using the following operating parameters: initial shooting pressure of $6 \mathrm{bar}$, shot time $4 \mathrm{~s}$ and $2 \mathrm{~s}$, core-box temperature 200,250 and $300{ }^{\circ} \mathrm{C}$ and core heating time $30,60,90$ and $150 \mathrm{~s}$. Matrixes of the moulding sands were two types of high-silica sand: fine and medium. Moulding sand binder was a commercial, unmodified hydrated sodium silicate having a molar module $\mathrm{SiO}_{2} / \mathrm{Na}_{2} \mathrm{O}$ of 2.5. In one shot of a core-shooter were made three longitudinal samples (cores) with a total volume of about $2.8 \mathrm{dm}^{3}$. The samples thus obtained were subjected to an assessment of the effect of shooting parameters, i.e. shooting time, temperature and heating time, using the criteria: core-box fill rate, bending strength $\left(\mathrm{R}_{\mathrm{g}}^{\mathrm{U}}\right)$, apparent density and surface quality after hardening. The results of the trials on the use of sodium silicate moluding sands made it possible to further refine the conditions of next research into the improvement of inorganic warm-box / hot-box technology aimed at: reduction of heating temperature and shot time. It was found that the performance of the cores depends on the efficiency of the venting system, shooting time, filling level of a shooting chamber and grains of the silica matrix used.
\end{abstract}

Keywords: Foundry, Sodium silicate, Core-box, Core shooting, Bending strength

\section{Introduction}

Introducing automation of technological processes in foundry not only improves safety and hygiene but also has a positive impact on quality management. Automation of manufacturing systems [1] leads to increasing technological efficiency, production volume, product quality and cost reduction, by reducing the energy consumed in the process and also reducing material losses. This is particularly important in the production of castings requiring high accuracy without any additional machining. In order to ensure such production, there is a growing demand for high quality moulds, such as ecological and economic cores. This trend favors the development of specialized machinery and foundry equipment, including: core-shooter device [2].

The advantage of modern core-shooters is their versatility and high degree of automation. They can successfully work in the following technologies: hot-box, warm-box, cold-box [3] and in warm-air [4] or $\mathrm{CO}_{2}$ [5] processes. Particularly interesting are the solutions combining the advantages: properly designed [2, 6] shooting and venting device with simulation [2], selection and control of sand filling parameters $[2,7,8,9]$, keeping time in a 
core-box $[9,10]$ with modern inorganic molding mixtures [11, 12].

Combining the advantages of an automated molding machine equipped with a system of full control and stabilization of the process with sands technology with eco-friendly inorganic binders can be an excellent alternative for perfected cold-box processes $[3,13]$. Sands with hydrated sodium silicate that can successfully be hardened by classical drying [14] or air-dried [4, 15], based on the idea of hot-box molding can be an example.

Hydrated sodium silicate as a binder for moulding sand has a higher than organic binders temperature strength, because of its inorganic character, which make them ideal for applications in cast steel production [16] and for other kinds of ferrous and nonferrous alloys. Also, its' eco-friendly character and low-emission of harmful substances was confirmed in the research [17]. With the use of physical methods of drying, i.e. microwave heating [18], the binder content can be substantially reduced while preserving hydrophilic properties [19-22] of sodium silicate film. This advantages can be successfully used in reclaim methods [19] reducing the costs of casting.

When operating at temperatures significantly above the minimum drying air temperature: $10-30^{\circ} \mathrm{C}$ [15] or $60-80{ }^{\circ} \mathrm{C}$ [4] or $100{ }^{\circ} \mathrm{C}$ [14] or as given in [10]: $125-200{ }^{\circ} \mathrm{C}$ necessary to remove water contained in colloidal silica binder, there is no detailed information on mechanical and technological parameters hardened (dried) above $200{ }^{\circ} \mathrm{C}$. In the case of moulding sands with organic binders, which include phenolic-formaldehyde resins, elevated temperature used in the hot-box process is necessary, in the case of rapid, due to the production cycle of cores in hot-box with hydrophilic binders such as hydrated sodium silicate, is not fully explained. As an example of the influence of temperature on sandmix cylindrical samples subjected to physical drying, it is possible to use Figure 1, which shows behavior of a hardened at $100{ }^{\circ} \mathrm{C}$ moulding mixture, which after heating at elevated temperatures and cooled down to ambient temperature was studied at its retained (residual) strength $\left(\mathrm{R}_{\mathrm{c}}^{\mathrm{tk}}\right)$. As it can be seen from Figure 1, under heating at temperatures $350-400{ }^{\circ} \mathrm{C}$ there is a significant drop in cured sand strength. Will similar phenomena be accompanied by hydrated sodium silicate sands, at the stage of hardening in hot core-box, should be further explained in the presented paper. In used sands with hydrated sodium silicate subjected to elevated temperatures it can be also noted that there is tendency for secondary hydration $[19,20]$ of the binder in humid environment.

\section{Purpose and scope of the research}

Due to the previously proved tendency to lose strength because of thermal impact on unhardened molded sand with inorganic binder [9], in the range above the used ones in classical drying process, efforts have been made to explain influence of an increased, above $200{ }^{\circ} \mathrm{C}$ to $300{ }^{\circ} \mathrm{C}$ temperature of a core-box . In addition, when using warm-box or hot-box technology to produce high-quality casting cores from hydrated sodium silicate, it is necessary to assess the impact of the methods based on sands' heating in core-boxes on their (samples) surface quality.

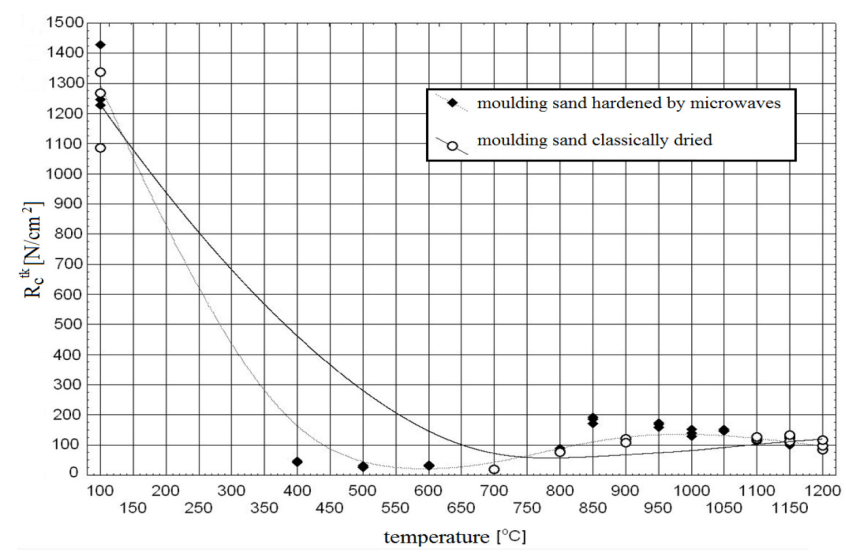

Fig. 1. Retained strength of physically hardened moulding sands at temperature of about $100^{\circ} \mathrm{C}$. Sandmix: medium silica sand, $2.5 \%$ wt. binder with a molar modulus of $\mathrm{SiO}_{2} / \mathrm{Na}_{2} \mathrm{O}$ equal 2.0

Three longitudinal samples (symbolizing foundry cores) were used to test for the effect of elevated heating temperature in order to cured sodium silicate sand which, were produced at LUT-c type semiautomatic core shooter (Fig. 2). The Multiserw-Morek company is the manufacturer of the core blower used in the tests. Semi-automatic operation of the core shooter required from an operator to replenish the blown moulding mixture of a shooting tank and manually receive three cores performed in one shot. The test results will be used to determine recommended blower device settings to produce eco-friendly cores from sands with inorganic binder in warm box/hot-box technology.

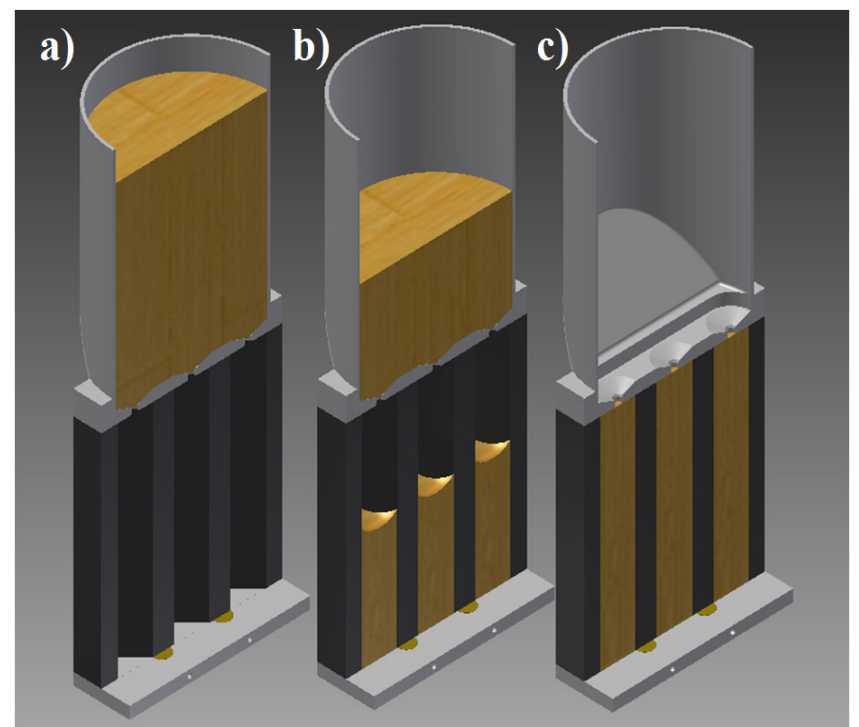

Fig. 2. Theoretical process of filling a three-slot core-box with sand at the shooting device: a) manually filled with sand shooting tank having a capacity of $3 \mathrm{dm}^{3}$, b) automatically filled slots of the core-box, c) core sand is heating by two $1.5 \mathrm{~kW}$ warmers

The moulding sands used in this research were prepared of dried and cooled-down high-silica coarse-size $1 \mathrm{~K}$ (main fraction $0.10 / 0.16 / 0.20$ ) and medium-size $1 \mathrm{~K}$ (main fraction 
0.20/0.315/0.16) sands from the mine "Grudzeń Las" and nonmodified sodium silicate (water-glass) grade 145 made by Chemical Works "Rudniki" S.A., see Table 1. A portion of $6 \mathrm{~kg}$ of moulding sand was prepared in a laboratory ribbon mixer. Per 100 weight parts of sand, 1.0 weight parts of water was dosed [14], in order to limit the expected phenomenon of too fast drying of the core shooting sand, and thus excessive friability. Next, after $60 \mathrm{~s}$ from starting the stirring process, 1.5 weight parts of the binder 145 were introduced, and mixing was continued for $240 \mathrm{~s}$.

Table 1.

Physico-chemical properties of sodium silicate used in the examined types (M1, M2) of moulding sands mixtures

\begin{tabular}{ccccccc}
\hline $\begin{array}{c}\text { Binder } \\
\text { grade: }\end{array}$ & $\begin{array}{c}\text { Molar } \\
\text { module } \\
\mathrm{SiO}_{2} / \mathrm{Na}_{2} \mathrm{O}\end{array}$ & $\begin{array}{c}\text { Oxide } \\
\text { content } \\
\left(\mathrm{SiO}_{2}\right. \\
\left.+\mathrm{Na}_{2} \mathrm{O}\right) \\
\%\end{array}$ & $\begin{array}{c}\text { Density } \\
\left(2{ }^{\circ} \mathrm{C}\right) \\
\mathrm{g} / \mathrm{cm}^{3}\end{array}$ & $\begin{array}{c}\mathrm{Fe}_{2} \\
\mathrm{Oax} \\
\%\end{array}$ & $\begin{array}{c}\mathrm{CaO} \\
\text { max. } \\
\%\end{array}$ & $\begin{array}{c}\text { Dynamic } \\
\text { viscosity } \\
\text { min. } \\
(\mathrm{P})\end{array}$ \\
\hline Type: & $\begin{array}{c}\text { Grain } \\
\text { size: }\end{array}$ & Binder: & $\begin{array}{c}\text { Wetting } \\
\text { agent }\end{array}$ & $\begin{array}{c}\text { Mass ratio: } \\
\text { matrix:binder:water }\end{array}$ \\
\hline $\mathrm{M} 1$ & coarse & 145 & yes & & $100: 1.5: 1$ \\
\hline $\mathrm{M} 2$ & medium & 145 & yes & & $100: 1.5: 1$ \\
\hline
\end{tabular}

A research plan provided performance of a series of longitudinal samples (cores) for various operating settings of the core shooter device. The research included determination of the influence of parameters such as:

$>\quad$ shot time: $2 \mathrm{~s}, 4 \mathrm{~s}$;

$>\quad$ heating temperature: 200,250 i $300{ }^{\circ} \mathrm{C}$;

$>$ heating time: $30,60,90$ i $150 \mathrm{~s}$.

Due to increased water content that reduces the viscosity of molding sands [11], a maximum initial shooting pressure of 6 bar was assumed for all test cycles. With equal and repetitive filling of $3 \mathrm{dm}^{3}$ shooting tank with an sifted sand (Fig. 2a), constant shoot pressure allowed comparison of the longitudinal samples obtained in the hot-box processes. Evaluation of mechanical strength on bending, after hardening and cooling, was carried out at a LRuE-2e station delivered by Multiserw-Morek.

Evaluation included the results of: apparent density measurements of correctly produced samples, as well as a visual assessment of the surface quality during manual maneuvering of the cores as their tendency for friability.

\section{Results}

In order to avoid dimensional defects' occurrence shown in Figure 3, the structure of the shooting tank head was adjusted in the first place in such a way as to ensure adequate venting of the shooting tank - core-box configuration when it is filled with moulding mixture. The defect most frequently observed was incomplete, as about $50 \%$ filling of a single cavity in a core-box (Fig. 3a). Therefore, a venting channels' shape was changed (Fig. $3 \mathrm{c}$ ) and cross-sections have become larger by a dozen percent.

In preliminary research on the possibility of using sands with sodium silicate to make cores in the warm-box / hot-box process, it was found that the initial shooting time of $4 \mathrm{~s}$ favors formation of air bubbles (Fig. 3b). Initially accepted, 4-second shooting time resulted in a significant reduction in the performance of proper cores for both M1 and M2 sands. It was found that for a given volume of core-box's cavity, constant pressure (6 bar) and degree of shooting tank filling, further tests will be performed with a shortened to $2 \mathrm{~s}$ shooting time. This also made it possible to partially minimize crater formation in the shooting tank.

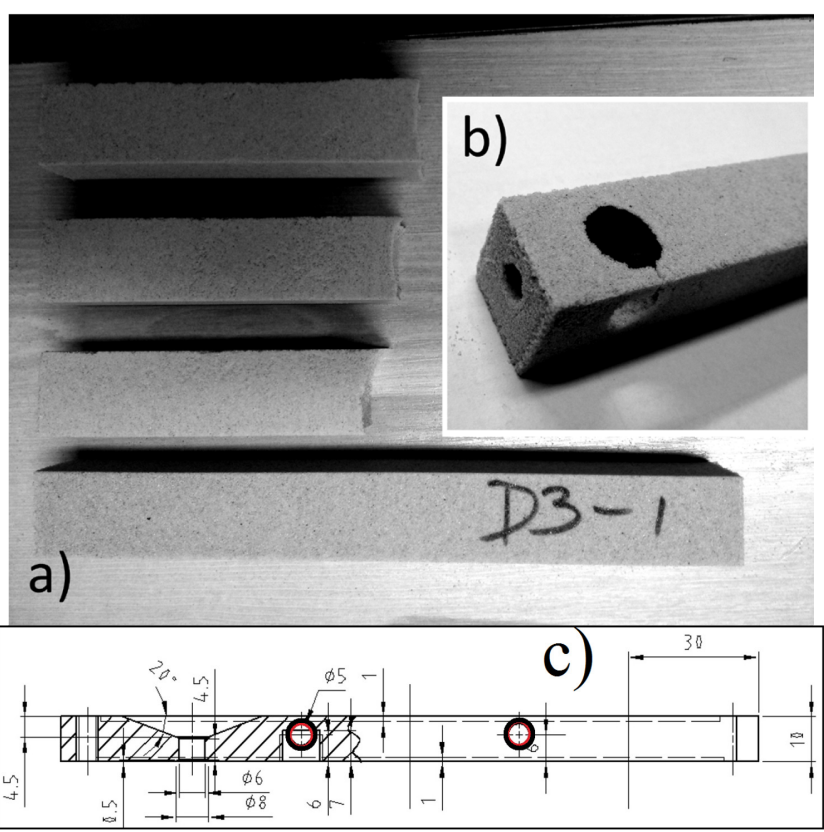

Fig. 3. Example of dimensionally-shaped defects of cores created by non-conformation of sand composition with: a) an ineffective venting system of core-box's cavities, b) too long shooting time,

c) example of two places with larger venting channels

Figures 4 and 5 show apparent densities measurements after heating and cooling of properly formed cores after a $2 \mathrm{~s}$ shot with no dimensional - shape defects.

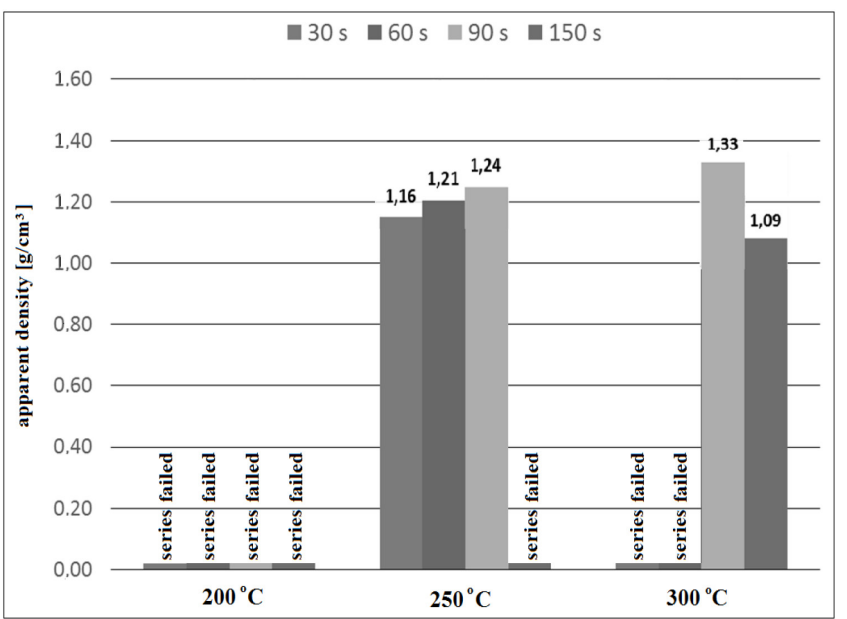

Fig. 4. Apparent density of hardened moulding sands M1 with different core-shooter settings 


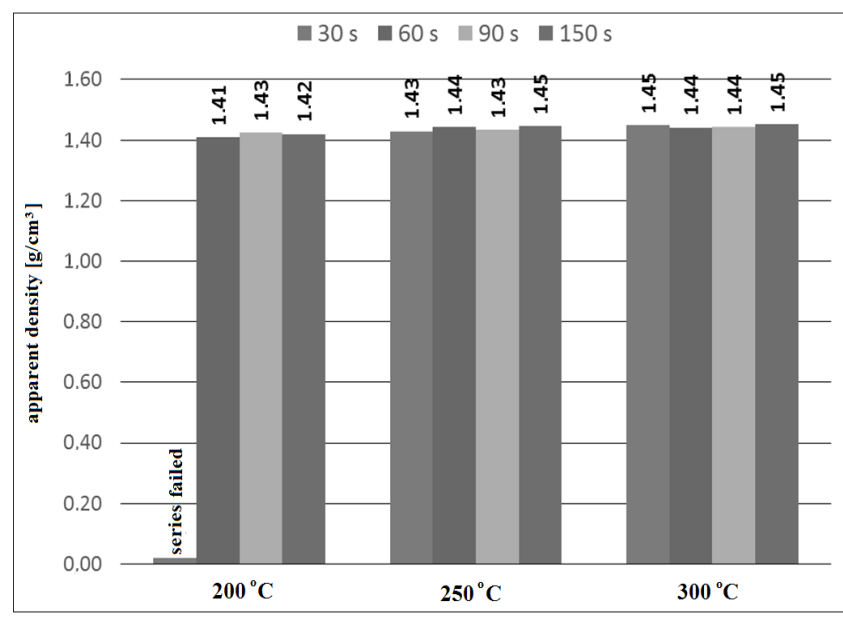

Fig. 5. Apparent density of hardened moulding sands M2 with different core-shooter settings

Successful series of attempts allowed to further evaluate the impact of the shots accompanying parameters on apparent density of sands. For M1 sand (Fig. 4), apparent density ranged from 1.09 to $1.33 \mathrm{~g} / \mathrm{cm}^{3}$ (fine sand), and for M2 (Fig. 5) from 1.41 to 1.45 $\mathrm{g} / \mathrm{cm}^{3}$ (medium sand).

Sand made on a fine matrix, due to a larger proper surface area and reduced binder viscosity by addition to the matrix of $1 \%$ wt. of water proved to be a much more demanding core mixture in the shooting process than a traditional: manual or vibratory compaction [19]. As a result of linking the settings of the core shooter with moulding sand parameters there was small, as not exceeding 33\%, "efficiency" in some series. Efficiency is defining the number of well-performed cores (Tab. 2). A series of cores heated at $200{ }^{\circ} \mathrm{C}$ were unsuccessful, indicating that despite the repetition of shooting they did not produce at least two samples deprived of dimensional-shaped defects related to improper filling (Fig. 3a) of the core-box cavities. The same filling problem was observed at $300{ }^{\circ} \mathrm{C}$, but some series with heating time of $90 \mathrm{~s}$ and $150 \mathrm{~s}$ have higher efficiency (see Tab. 2). After shooting and heating, some cores, with proper dimensions, had air bubbles inside (Fig. 3b). Probably, the number of defects may be reduced by shortening the shooting time to less than $2 \mathrm{~s}$.

Average apparent density of M1 and M2 sands which was achieved after shooting and hardening was measured for the sands from same mine $[14,20]$ after conventional vibration compaction ( $\mathrm{f}=50 \mathrm{~Hz}, 120 \mathrm{~s}$ vibration amplitude of about $1 \mathrm{~mm}$ ). Despite a satisfactory degree of samples compaction made from M1 sand in series heated at $250{ }^{\circ} \mathrm{C}$, hidden interior air bubbles were found, and on the surface of all cores a high tendency for excessive friability during manual maneuvering.

The use of medium grain matrix M2 was much more advantageous (see Tab. 1). Samples made of medium sand exhibited significantly better qualitative parameters (Tab. 3) than those of M1. There was no effect of excessive friability on their surface connected to drying or dimensional-shape errors preventing performance of the correct cores in the series. Problems appeared to be small, rarely occurring air bubbles, and in the case of the $200{ }^{\circ} \mathrm{C} / 30 \mathrm{~s}$, there was no full hardening (see Fig. 6), due to short preheating time in a closed core-box.
Table 2.

Quality assessment of M1 sand cores - shot time 2s

\begin{tabular}{|c|c|c|c|}
\hline \multirow{2}{*}{$\begin{array}{l}\text { Heating } \\
\text { time }\end{array}$} & \multicolumn{3}{|c|}{ Core-box temperature $\left[{ }^{\circ} \mathrm{C}\right]$} \\
\hline & 200 & 250 & 300 \\
\hline $30 \mathrm{~s}$ & $\begin{array}{l}\text { series failed } \\
\bullet \text { Efficiency: } \\
0-33,3 \% \\
\text { - lack of } \\
\text { filling }\end{array}$ & $\begin{array}{l}\text { series failed } \\
\text {-Efficiency: } 0 \\
33,3 \% \text {, } \\
\text { - great friability } \\
\text { - air bubble } \\
\bullet 70 \% \text { of core-box } \\
\text { filling }\end{array}$ & $\begin{array}{l}\text { series failed } \\
\bullet \text { Efficiency: } 0- \\
33,3 \% \text {, } \\
\bullet \text { lack of filling }\end{array}$ \\
\hline $60 \mathrm{~s}$ & $\begin{array}{l}\text { series failed } \\
\bullet \text { Efficiency: } \\
0-33,3 \% \text {, } \\
\text { - lack of } \\
\text { filling }\end{array}$ & $\begin{array}{l}\text { successful series } \\
\text { - Efficiency } 66,7 \% \text {, } \\
\text { - great friability } \\
\text { - air bubble } \\
\text { - } 80 \% \text { of core-box } \\
\text { filling }\end{array}$ & $\begin{array}{l}\text { series failed } \\
\bullet \text { efficiency: } 0- \\
33,3 \% \text {, } \\
\bullet \text { lack of filling }\end{array}$ \\
\hline $90 \mathrm{~s}$ & $\begin{array}{l}\text { series failed } \\
\bullet \text { Efficiency: } \\
0-33,3 \% \text {, } \\
\text { - lack of } \\
\text { filling }\end{array}$ & $\begin{array}{l}\text { successful series } \\
\bullet \text { Efficiency } 66,6 \\
100 \%, \\
\bullet \text { great friability } \\
\text { air bubble }\end{array}$ & $\begin{array}{l}\text { successful series } \\
\bullet \text { Efficiency } \\
100 \%, \\
\text { - great friability } \\
\text { - air bubble }\end{array}$ \\
\hline $150 \mathrm{~s}$ & $\begin{array}{l}\text { series failed } \\
\bullet \text { Efficiency: } \\
0-33,3 \% \text {, } \\
\text { - lack of } \\
\text { filling }\end{array}$ & $\begin{array}{l}\text { series failed } \\
\text { - Efficiency: } \quad 0 \\
33,3 \% \text {, } \\
\text { - great friability } \\
\text { - air bubble } \\
\text { - } 70 \% \text { of core-box } \\
\text { filling }\end{array}$ & $\begin{array}{l}\text { Successful series } \\
\text {-Efficiency: } \\
66,7 \% \\
\text { - air bubble } \\
\bullet 70 \%-85 \% \text { of } \\
\text { core-box filling }\end{array}$ \\
\hline
\end{tabular}

Table 3.

Quality assessment of M2 sand cores - shot time $2 \mathrm{~s}$

\begin{tabular}{|c|c|c|c|}
\hline Heating & & ore-box temperature & \\
\hline time & 200 & 250 & 300 \\
\hline & series failed & successful series & successful series \\
\hline & - Efficiency: & - $\quad$ Efficiency & Efficiency: \\
\hline $30 \mathrm{~s}$ & $0 \%$ & $100 \%$ & $100 \%$, \\
\hline & $\begin{array}{l}\bullet \text { lack of } \\
\text { hardening }\end{array}$ & $\begin{array}{l}\text { - great friability, } \\
\text { - air bubble, }\end{array}$ & \\
\hline & successful & successful series & successful series \\
\hline & series & - $\quad$ Efficiency & Efficiency: \\
\hline & - Efficiency: & $66,7 \%$ & $100 \%$, \\
\hline $60 \mathrm{~s}$ & $100 \%$ & - great friability, & - great friability, \\
\hline & - partial lack & - air bubble, & \\
\hline & of hardening & $\bullet 70 \%$ of core-box & \\
\hline & - air bubble & filling, & \\
\hline & successful & successful series & successful series \\
\hline & series & Efficiency & Efficiency: \\
\hline $90 \mathrm{~s}$ & - Efficiency: & $66,7 \%$ & $100 \%$ \\
\hline & $\begin{array}{l}100 \% \text {, } \\
\text { • air bubble, }\end{array}$ & $\begin{array}{l}\text { - air bubble, } \\
\text { - } 70 \% \text { of core-box } \\
\text { filling }\end{array}$ & - great friability, \\
\hline & successful & successful series & successful series \\
\hline & series & Efficiency & -Efficiency: \\
\hline $150 \mathrm{~s}$ & - Efficiency: & $100 \%$, & $100 \%$ \\
\hline & $\begin{array}{l}100 \% \text {, } \\
\bullet \text { air bubble, }\end{array}$ & & - great friability \\
\hline & $\theta$ & & \\
\hline
\end{tabular}

With shooting parameters set for core shooter, for the series of hot-box dried and cooled-down longitudinal samples, it was possible to further evaluate the achieved mechanical strength. The results of bending strength tests $\left(\mathrm{R}_{\mathrm{g}}^{\mathrm{U}}\right)$, which are an arithmetic mean of at least 2 determinations, are shown in Figures 7 and 8. 


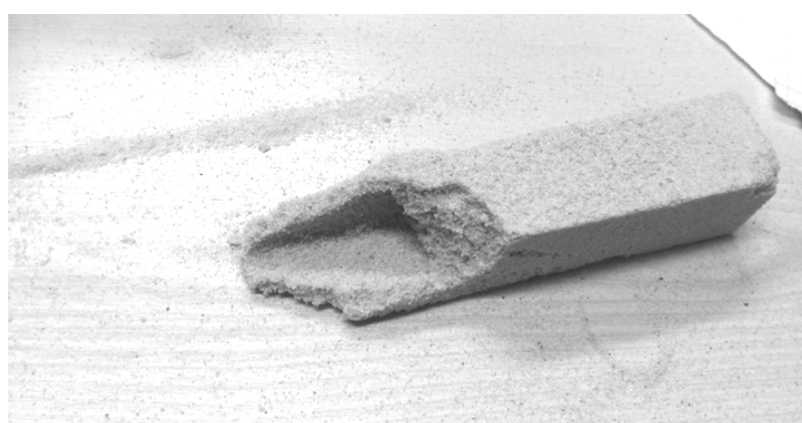

Fig. 6. The M2 sand: incomplete core's curing inside a crosssection of a sample in the series of $200{ }^{\circ} \mathrm{C} / 30 \mathrm{~s}$

As can be seen from the comparison of Figures 7 and 8, it is preferable, in the case of an inorganic binder with a molar module of $2.5\left(\mathrm{SiO}_{2} / \mathrm{Na}_{2} \mathrm{O}\right)$, to use a medium silica sand as a matrix. In addition, based on the results of M2 sand analyzes, a preliminary research of the effect of the core shooting parameters on the quality of the cores can be continued.

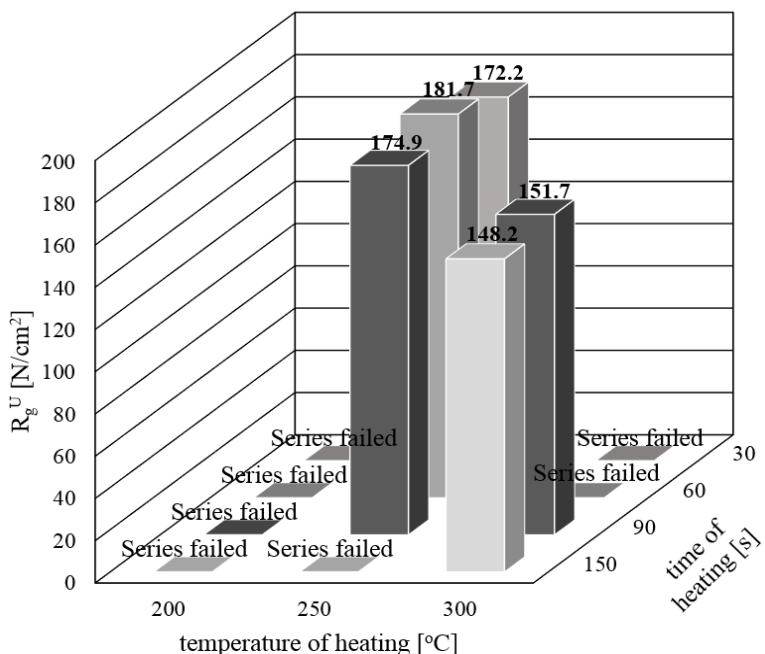

Fig. 7. Effect of curing time and heating teperature on bending strength $\mathrm{R}_{\mathrm{g}}^{\mathrm{U}}$ of moulding sand $\mathrm{M} 1$

In the case of moulding sand M1 (Fig. 7), the quality of the cores enabled determining their bending strength only for the core-box heated to $250{ }^{\circ} \mathrm{C}$, but without the series with the longest heating time. The $\mathrm{R}_{\mathrm{g}}^{\mathrm{U}}$ bending strength of the proper cores ranged from 172 to $182 \mathrm{~N} / \mathrm{cm}^{2}$. Increasing the core-box temperature by another $50{ }^{\circ} \mathrm{C}$ for series in which there was $90 \mathrm{~s}$ heating time resulted in a $15 \%$ loss in bending strength.

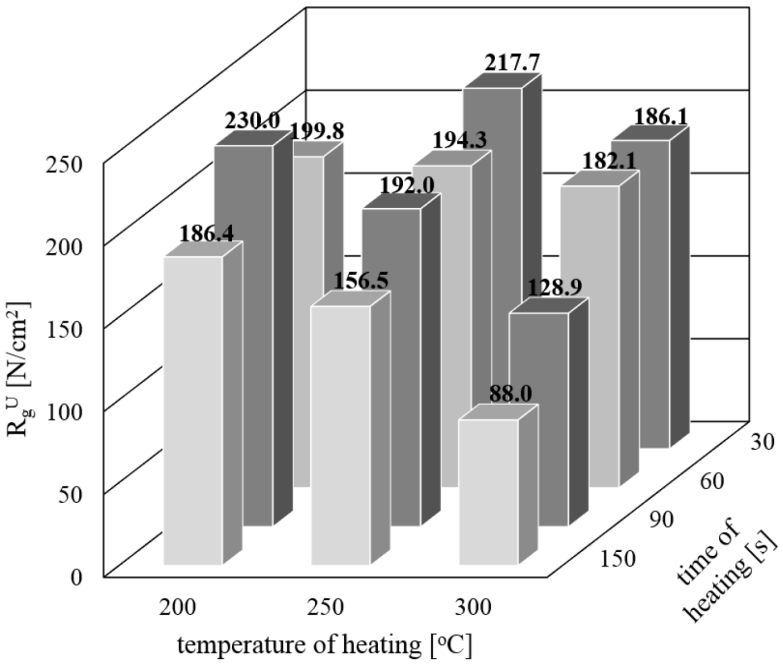

Fig. 8. Effect of curing time and heating teperature on bending strength $\mathrm{R}_{\mathrm{g}}{ }^{\mathrm{U}}$ of moulding sand $\mathrm{M} 2$

Much more can be said about the influence of core-shooter settings on the bending strength parameters for hardened cores out of moulding sand M2. By analyzing the diagram of Figure 8, two distinct tendencies can be identified, with hot-box parameters of $300{ }^{\circ} \mathrm{C} / 150 \mathrm{~s}$ being the starting point. The lowest average bending strength is only $88 \mathrm{~N} / \mathrm{cm}^{2}$ for the adopted temperature and heating time settings. As the temperature was reduced to 250 and $200{ }^{\circ} \mathrm{C}$, bending strength increased by $78 \%$ and $112 \%$, respectively. The second, revealed tendency shows the effect of reducing preheating time in a core-box. For the series $200{ }^{\circ} \mathrm{C} / 90$ $\mathrm{s}$, referring to $\mathrm{R}_{\mathrm{g}}^{\mathrm{U}}$ output (at series $300{ }^{\circ} \mathrm{C} / 150 \mathrm{~s}$ ), an increase of $261 \%$ can be observed (Fig. 8). Reducing time in the $200{ }^{\circ} \mathrm{C}$ series resulted in incomplete hardening of the cores during the molding process, resulting in a reduction in bending strength from $230 \mathrm{~N} / \mathrm{cm}^{2}$ to about $200 \mathrm{~N} / \mathrm{cm}^{2}$. Further reduction of heating time causes insufficient drying of the cores (Fig. 6). It is also interesting to use heating temperature of $250{ }^{\circ} \mathrm{C}$ in combination with a very short time $(30 \mathrm{~s})$ in the core-box. The cores performed in this way, however, were characterized with larger friability than those analyzed earlier (Table 3 ).

A temperature of $300{ }^{\circ} \mathrm{C}$ and short heating time ( $\left.30 \mathrm{~s}\right)$ may be preferable to the point of short cycle production, since there were no cases with excessive friability or any other dimensional-shape defects in these series, while maintaining good bending strengths of approximately $186 \mathrm{~N} / \mathrm{cm}^{2}$.

\section{Conclusions}

The tendency for dimensional or shape defects if there is a lack of core filling or air bubbles is directly related to the effectiveness of nozzle venting system in the shooting head of a pressure-forming device. Partial elimination of these defects can be achieved by properly modifying the shoot-and-vent system for a particular type of core.

It should be noted, however, that the quality of warm-box / hot-box cores depends to a large extent on silica sand granularity 
which was used. The thicker the sand, the smaller the shooting resistance due to smaller surface area of the moulding sand matrix.

The conducted analysis of the test results clearly indicates decrease in bending strength of the cores with the increase in the heating temperature and preheating time of sand in the core-box. This conclusion was found on the basis of researches with medium silica sand matrix.

The best mechanical properties of the tested samples had the cores heated at $200-250{ }^{\circ} \mathrm{C}$ for $60-90 \mathrm{~s}$. After cooling-down the samples, their bending strength reached about $200 \mathrm{~N} / \mathrm{cm}^{2}$.

During cross-sectional studies of cores that had been heated for 30 seconds at $200{ }^{\circ} \mathrm{C}$, there was no full hardening of the moulding sand in the inner part of the core. In the case of tests when the sands were heated for the shortest time, it would probably be advantageous to use additional, rapid drying by microwave heating.

The performed tests also confirmed that, at a constant 6 bar shooting pressure, set points parameters of the device (shot time and temperature of the core-box) did not significantly affect the degree of moulding sand apparent density.

Due to the ecological character of silica sands with hydrated sodium silicate, it is advisable to continue work with other (with different viscosity) kinds of binders to check the impact of process parameters on the quality of the cores. At this stage, moulding sands with hydrated sodium silicate represent a major research and practical challenge in this area.

\section{Acknowledgement}

The research was financially supported from the grant for statutory activity No. 0401/0084/16.

\section{References}

[1] Samsonowicz, Z. (1986). Engineer's Guide. Casting. Volume 1 Chapter VIII Warszawa: Wydawnictwo NaukowoTechniczne, 886. (in Polish).

[2] Dańko, J. (1992). Process of casting cores and molds by blowing methods. Research and theory. Metalurgia $\mathrm{i}$ odlewnictwo. Zeszyt 145 Zeszyty naukowe AGH im. Stanisława Staszica. (in Polish).

[3] González, R. \& Colás, R. (2011). Characteristics of Phenolic-Urethane Cold Box Sand Cores for Aluminum Casting. International Journal of Metalcasting. 5(1), 41-48.

[4] Izdebska-Szanda, I., Kamińska, J., Angrecki, M., Palma, A. \& Madej W. (2016). An innovative method for the dehydration hardening of modified inorganic binders. Archives of Metallurgy and Materials. 61(4), p. 2097-2102.

[5] Kim, E.-H., Lee, J.-H., Jung, Y.-G., Jang, J.-Ch. \& Paik, U. (2013). Control of $\mathrm{H}_{2} \mathrm{O}$ generated during $\mathrm{CO}_{2}$ hardening process in a casting mold. Ceramics International. 39, 39933998.

[6] Nowalczyk., Ch. (2014). Core firing simulation - as an economic and ecological asset of the casting process Przeglad Odlewnictwa. 11-12, 472-474. (in Polish).
[7] Dańko, J., Zych, J. \& Dańko, R. (2009). Diagnostic methods of technological properties and casting cores quality. Archives of Metallurgy and Materials. 54 (3), 381-392.

[8] Ganesh, R. Chate, Bhat, R.P. \& Chate, U.N. (2014). Process parameter settings for core shooter machine by taguchi approach. Procedia Materials Science. 5, 1976-1985.

[9] Dańko, R., Dańko, J., Burbelko, A. \& Skrzyński, M. (2014). Core Blowing Process - Assessment of Core Sands Properties and Preliminary Model Testing. Archives of Foundry Engineering. 14(1), 25-28.

[10] Fedoryszyn, A., Dańko, J., Dańko, R., Asłanowicz, M., Fulko, T. \& Ościłowski, A. (2013). Characteristic of Core Manufacturing Process with Use of Sand, Bonded by Ecological Friendly Nonorganic Binders. Archives of Foundry Engineering. 13(3), 19-24.

[11] Schrey, A. (2007). The new environment-friendly binder system SOLOSIL TX for core making for the mass production of complex cast components. Foundry Practice. $263,15-23$.

[12] Izdebska-Szanda, I. \& Balinski, A. (2011). New generation of ecological silicate binders. Procedia Engineering. 10, 887-893.

[13] Zych, J. (2013). Pulsating Gas Dosage in the Moulding Sands Hardening Process in the Cold-Box Technology. Archives of Metallurgy and Materials. 58(3), 837-840.

[14] Stachowicz, M., Granat, K. \& Pałyga, Ł. (2016). The effect of wetting agent on the parameters of dry moulding silica sands bonded with sodium water glass. Transactions of the Foundry Research Institute. 56(1), 43-55.

[15] Zych, J. (2007). Behaviour of moulding sands with hydrophilic binders in dry air. Archives of Foundry Engineering. 7(4), 189-192.

[16] Fan, Z., Huang, N.Y. \& Dong, X.P. (2004). In house reuse and reclamation of used foundry sands with sodium silicate binder. International Journal of Cast Metals Research. 177(1), 51-56.

[17] Ji, S., Wan, L. \& Fan, Z. (2001). The Toxic Compounds and Leaching Characteristics of Spent Foundry Sands. Water Air and Soil Pollution. 132(3), 347-364.

[18] Wang J., Fan Z. \& Zan X. (2009). Properties of sodium silicate sand hardened by microwave heating. China Foundry. 6(03), 191-196.

[19] Stachowicz, M. \& Granat, K. (2017). Influence of wet activation of used inorganic binder on cyclically refreshed water glass moulding sands hardened by microwaves. China Foundry. 13(6), 427-432.

[20] Liu, F.C., Fan, Z.T., Liu, X., Huang, Y. \& Jiang, P. (2016). Effect of surface coating strengthening on humidity resistance of sodium silicate bonded sand cured by microwave heating. Materials and Manufacturing Processes. 31, 1639-1642.

[21] Wang, H.F., Lu, J.J., Chen, K.F. \& Duan, H.L. (2015). Harmless treatment of used foundry sands and dewatered municipal sludge by microwave. Metalurgija. 54(3), 459461.

[22] Wang, H.F., Fan, Z.T., Yu, S., Liu, F.C. \& Li, X. (2012). Wet reclamation of sodium silicate used sand and biological treatment of its wastewater by Nitzschia palea. China Foundry. 9(1), 34-38. 